Observation

\section{IA-2 is not required for the development of diabetes in NOD mice}

To the Editor: IA-2 is a major autoantigen in Type 1 diabetes mellitus [1]. Autoantibodies to IA-2 are detected in approximately $70 \%$ of newly diagnosed Type 1 diabetes patients and in less than $1 \%$ of the control subjects. Based on sequence analysis, IA-2 is an enzymatically inactive transmembrane protein tyrosine phosphatase and is located in secretory vesicles of neuroendocrine cells, particularly pancreatic islets and brain cells. IA-2 knockout studies in mice showed elevated glucose tolerance tests and depressed insulin release [2]. Islets isolated from IA-2-l- mice showed less insulin release as compared to islets from $\mathrm{IA}-2^{+/+}$mice when the cultures were switched from basal $(3.3 \mathrm{mmol} / \mathrm{l})$ to high glucose $(27.7 \mathrm{mmol} / \mathrm{l})$ concentrations. These and other studies argue that IA-2 is involved in insulin secretion.

The non-obese diabetic (NOD) mouse is the most widely studied animal model for Type 1 diabetes [3]. Gene linkage analyses have identified at least 19 susceptibility loci (IddIIdd19). The murine IA-2 gene (Ptprn) is located on chromosome $1(41 \mathrm{cM})$ and is a potential candidate gene for Idd5.2 [4]. The role of IA-2 in the NOD mouse model, however, has not been determined.

In the present study, IA-2+/- mice (129/Sv x C57BL/6) were backcrossed to NOD/LtJ mice (Jackson Laboratory, Bar Harbor, Me., USA) for eight generations. IA- $2^{+-}$NOD mice then were intercrossed to obtain IA-2-/- NOD mice. All protocols were approved by our Institutional Animal Care and Use Committees. The IA-2 genotypes were determined by PCR using specific primers for the targeted locus and for the wild-type locus [2]. IA-2 protein expression in brain, analysed by Western blot, showed the presence of IA-2 in IA-2+/+ NOD mice, but its absence in IA-2 $2^{-/-}$NOD mice (Fig. 1). IA-2+/+ NOD and IA-2I- NOD mice then were injected with cyclophosphamide, a known accelerator of diabetes in NOD mice [5]. Animals were followed twice a week and mice with two consecutive nonfasting blood glucose determinations with values above $250 \mathrm{mg} / \mathrm{dl}$ were scored as diabetic. As seen in Fig. 1, 44.4\% of IA $-2^{+/+}$NOD and $36.4 \%$ of IA-2-/- NOD mice developed diabetes. Histologic examination of pancreatic islets from these animals showed insulitis. The number of IA-2-/- NOD mice in our colony is still small, but five mice between 20 and 40 weeks of age already have developed diabetes spontaneously. Recently, we succeeded in knocking out IA-2 $\beta$, a protein closely related to IA-2, and its role in the development of diabetes in NOD mice is currently under investigation.

The knockout studies described here show that IA-2 is not required for the development of diabetes in NOD mice and earlier knockout studies showed that glutamic acid decarboxylase 65 (GAD65) also is not required for the development of diabetes in NOD mice [6]. Although there is some evidence in NOD mice that these antigens could be involved in a cell-mediated immune response [7], little if any autoantibodies are made to IA-2 or GAD65 in NOD mice [8]. In contrast to NOD mice, close to $90 \%$ of newly diagnosed patients with Type 1

DOI $10.1007 / \mathrm{s} 00125-003-1252-\mathrm{z}$

Received: 28 July 2003 / Revised: 26 September 2003

Published online: 12 November 2003

C) Springer-Verlag 2003

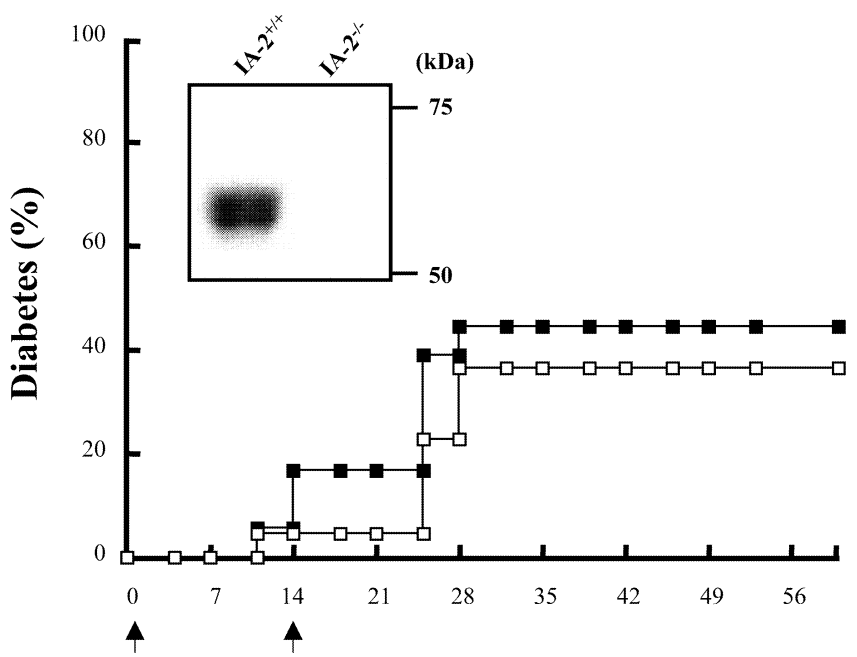

Days After Cyclophosphamide

Fig. 1. Development of diabetes in IA-2-/- NOD mice. Eightweek-old IA-2+/+ NOD $(\boldsymbol{\square}, n=18)$ and IA-2 $2^{-/-}$NOD $(\square, n=22)$ female mice were treated (arrows) with cyclophosphamide $(250 \mathrm{mg} / \mathrm{kg}$ i.p.) on days 0 and 14 and the percent that developed diabetes was determined. Insert shows Western blot

diabetes have autoantibodies to IA-2 and/or GAD65 and these autoantibodies have become important predictive markers [9]. Thus, there are major differences between the NOD mouse model and the human disease. Although IA-2 is not involved in the diabetes of NOD mice, the extent to which the autoimmune response to IA-2 may contribute to the pathogenesis of Type 1 diabetes in humans has yet to be solved.

A. Kubosaki, J. Miura, Abner L. Notkins

Experimental Medicine Section, Oral Infection and Immunity Branch, National Institute of Dental and Craniofacial Research, National Institutes of Health, Bethesda, Maryland, USA

Notkins

National Institutes of Health, Bethesda, USA

\section{References}

1. Lan MS, Wasserfall C, Maclaren NK, Notkins AL (1996) IA-2, a transmembrane protein of the protein tyrosine phosphatase family, is a major autoantigen in insulin-dependent diabetes mellitus. Proc Natl Acad Sci USA 93:6367-6370

2. Saeki K, Zhu M, Kubosaki A et al. (2002) Targeted disruption of the protein tyrosine phosphatase-like molecule IA-2 results in alterations in glucose tolerance tests and insulin secretion. Diabetes 51:1842-1850

3. Atkinson MA, Leiter EH (1999) The NOD mouse model of type 1 diabetes: as good as it gets? Nat Med 5:601-604

4. Leiter EH, Tsumura H, Serreze DV et al. (1997) Mapping to chromosomes 1 and 12 of mouse homologs of human protein tyrosine phosphatase, receptor-type, related genes encoding pancreatic beta cell autoantigens. Mamm Genome 8:949-950

5. Winer S, Astsaturov I, Gaedigk R et al. (2002) ICA69(null) nonobese diabetic mice develop diabetes, but resist disease acceleration by cyclophosphamide. J Immunol 168:475482 
6. Kash SF, Condie BG, Baekkeskov S (1999) Glutamate decarboxylase and GABA in pancreatic islets: lessons from knock-out mice. Horm Metab Res 31:340-344

7. Trembleau S, Penna G, Gregori S et al. (2000) Early Th1 response in unprimed nonobese diabetic mice to the tyrosine phosphatase-like insulinoma-associated protein 2 , an autoantigen in type 1 diabetes. J Immunol 165:6748-6755

8. Bonifacio E, Atkinson M, Eisenbarth G et al. (2001) International Workshop on Lessons From Animal Models for Human Type 1 Diabetes: identification of insulin but not glutamic acid decarboxylase or IA-2 as specific autoantigens of humoral autoimmunity in nonobese diabetic mice. Diabetes 50:2451-2458

9. Notkins AL (2002) Immunologic and genetic factors in type 1 diabetes. J Biol Chem 277:43545-43548

Abner L. Notkins MD ( $\bullet$ ), National Institutes of Health, Building 30, Room 121, 30 Convent Drive, MSC 4322, Bethesda, MD 20892-4322 USA

E-mail: anotkins@mail.nih.gov

\section{Observation}

\section{Abnormal ghrelin secretion in new onset childhood Type 1 diabetes}

To the Editor: Ghrelin is a new circulating peptide hormone produced mainly by the stomach [1] and involved in the regulation of feeding behaviour and energy homeostasis [2]. The concentrations of ghrelin are low in obese subjects [3, 4] and high in anorexic subjects [5]. In normal subjects the ghrelin secretion is stimulated by fasting and reduced by feeding [6] and by oral glucose load [4]. The mechanism of hormone release from the A-like ghrelin-producing cells [7] of the gastric mucosa is not yet known.

We examined ghrelin concentrations in 22 children; 11 boys and 11 girls, age $16 \pm 3.6$ years (mean \pm SD), BMI 18.0 \pm $5.2 \mathrm{~kg} / \mathrm{m}^{2}$ (mean $\pm \mathrm{SD}$ ) with a new onset of Type 1 diabetes. Blood samples were obtained at diagnosis before and after

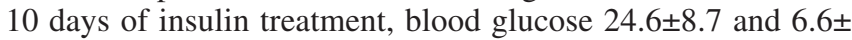
$3.0 \mathrm{mmol} / \mathrm{l}$, respectively, and in conjunction with meal tests, carried out in 15 and 20 of the cases at 3 and 9 months after the start of insulin therapy, respectively. At meal tests the patients were fasting over night and had received no insulin in the morning. Then they had a standardised breakfast $(20 \%$ of their daily energy intake, containing 33\% fat, 50\% carbohydrates and $17 \%$ proteins) and blood was drawn at time zero and after 30, 60, 90, 120, and $150 \mathrm{~min}$. Ghrelin was measured in the samples taken just before the test and when C-peptide reached its maximum. Ghrelin was determined in serum using a radioimmunoassay (Phoenix Pharmaceuticals, Belmont, Calif., USA), which uses ${ }^{125}$ I-labelled bioactive ghrelin as a tracer and a polyclonal antibody raised in rabbits against the fulllength, octanoylated human ghrelin. Intra-assay and inter-assay coefficients of variance were $5.3 \%$ and $13.6 \%$, respectively. Statistical significance was evaluated by Mann-Whitney U test and Wilcoxon signed rank test. The study was approved by the Research Ethics Committee at the Faculty of Health Sciences, Linköping.

Ghrelin concentrations at diagnosis prior to insulin treatment and after 10 days were $48.9 \pm 24.6$ and $74.3 \pm 61.5 \mathrm{pmol} / \mathrm{l}$

DOI 10.1007/s00125-003-1258-6

Received: 22 August 2003 / Revised: 29 September 2003

Published online: 12 November 2003

C) Springer-Verlag 2003 (mean $\pm \mathrm{SD})$, respectively $(p=0.007)$. Blood glucose and C-peptide values increased during the meal tests (Fig. 1), whereas no changes in serum ghrelin were observed; the ghrelin values before and after test meals were $61.9 \pm 43.9$ and $59.1 \pm 32.2 \mathrm{pmol} / 1$ at 3 months, and $93.4 \pm 72.4$ and $81.9 \pm 55.5 \mathrm{pmol} / \mathrm{l}$ at 9 months, respectively. In a group of ten healthy children, five boys and five girls with a mean age of 12 years, the fasting serum ghrelin concentration was $108.5 \pm 32.5 \mathrm{pmol} / \mathrm{l}$, ( $p=0.001)$, compared with the ghrelin values of the patients prior to insulin treatment.

To our knowledge, there are no previous reports on circulating ghrelin concentrations in patients with Type 1 diabetes. Patients with Type 2 diabetes were included in a previous study [6] which examined ghrelin concentrations in lean, normal weight and obese non-diabetic subjects and included observations on 42 subjects with Type 2 diabetes, 8 of whom were treated with diet alone, 22 with oral hypoglycaemic agents and 8 with insulin. Fasting plasma ghrelin concentration was negatively correlated with BMI in both subjects with Type 2 diabetes and those without. The plasma ghrelin concentrations of normal subjects decreased significantly after oral glucose administration, and a similar response was observed in patients with Type 2 diabetes after a meal tolerance test, reaching a nadir of $69 \%$ of the basal level after the meal. Similarly, a suppressive effect of a mixed liquid meal or oral glucose on serum ghrelin values in healthy human subjects was noted [8]. In contrast, we found that the children with Type 1 diabetes did not respond to meal tests with suppression of ghrelin values. One could speculate that ghrelin concentrations are low at di-
Glucose (mmol/L)

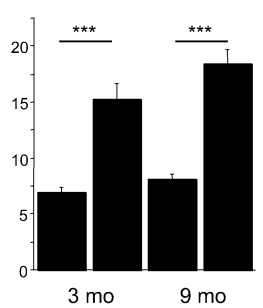

C-peptide (nmol/L)

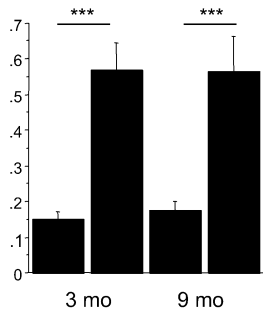

Ghrelin (pmol/L)

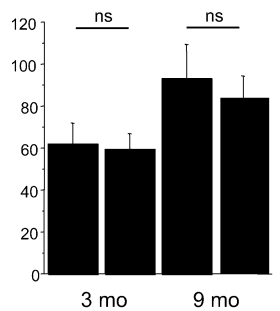

Fig. 1. Response to meal tests, carried out at $3(n=15)$ and 9 $(n=20)$ months after starting insulin treatment in childhood Type 1 diabetes. Results (mean \pm SEM) from pre- and postmeal blood samples at each time point; $* * * p<0.0001$; NS, nonsignificant 